SYMPOSIUM ON THE EFFICIENT USE OF SOLAR RADIATION IN PHOTOVOLTAIC POWER ENGINEERING (St. Petersburg, November 3-4, 2003)

\title{
Modeling Improvement of Spectral Response of Solar Cells by Deployment of Spectral Converters Containing Semiconductor Nanocrystals ${ }^{1}$
}

\author{
W. G. J. H. M. van Sark' 1 , A. Meijerink ${ }^{2}$, R. E. I. Schropp 2 , \\ J. A. M. van Roosmalen ${ }^{3}$, and E. H. Lysen ${ }^{4}$ \\ ${ }^{1}$ Copernicus Institute, Utrecht University, 3584 CH Utrecht, The Netherlands \\ e-mail:w.g.j.h.m.vansark@chem.uu.nl \\ ${ }^{2}$ Debye Institute, Utrecht University, 3584 CC Utrecht, The Netherlands \\ ${ }^{3}$ ECN Solar Energy, 1755 ZG Petten, The Netherlands \\ ${ }^{4}$ Utrecht Centre for Energy Research (UCE), Utrecht University, 3584 CH Utrecht, The Netherlands \\ Submitted February 16, 2004; accepted for publication February 16, 2004
}

\begin{abstract}
A planar converter containing quantum dots as wavelength-shifting moieties on top of a solar cell was studied. The highly efficient quantum dots are to shift the wavelengths where the spectral response of the solar cell is low to wavelengths where the spectral response is high in order to improve the conversion efficiency of the solar cell. It was calculated that quantum dots with an emission at $603 \mathrm{~nm}$ increase the multicrystalline solar cell short-circuit current by nearly $10 \%$. Simulation results for planar converters on hydrogenated amorphous silicon solar cells show no beneficial effects, due to the high spectral response at low wavelength. (O) 2004 MAIK "Nauka/Interperiodica".
\end{abstract}

\section{INTRODUCTION}

The fundamental spectral losses in a single-junction solar cell made of a semiconductor material such as silicon can be as large as 50\%. This is a result of the mismatch between the incident solar spectrum and the spectral absorption properties of the material [1]. Large parts of the solar spectrum are not absorbed because of the existence of a band gap $E_{g}$ of the material. Photons with energy $E_{\mathrm{ph}}$ larger than the band gap are absorbed, but the excess energy $E_{\mathrm{ph}}-E_{g}$ is not used effectively due to thermalization of the electrons. Photons with $E_{\mathrm{ph}}<E_{g}$ are not absorbed. Several routes have been proposed to overcome this intrinsic property of semiconductor solar cells and thereby increase the power output of solar cells. All these methods or concepts concentrate on a much better use of the solar spectrum and are in general referred to as third-generation photovoltaics [2].

Single-junction solar cells optimally perform under monochromatic light of a wavelength $\lambda_{\text {opt }} \simeq 1240 / E_{g}$. For (multi)crystalline silicon (mc-Si) solar cells, $\lambda_{\text {opt }}=$ $1100 \mathrm{~nm}$ (with $E_{g}=1.1 \mathrm{eV}$ ); for hydrogenated amorphous silicon (a-Si:H), the optimum wavelength is $\lambda_{\text {opt }}=700 \mathrm{~nm}$ (with $E_{g}=1.77 \mathrm{eV}$ ). As amorphous silicon solar cells only contain a thin absorber layer, the optimum spectrum response occurs at about $550 \mathrm{~nm}$ $[3,4]$. The conversion efficiency of these types of cells measured at incident monochromatic light of $550 \mathrm{~nm}$

\footnotetext{
${ }^{1}$ This article was submitted by the authors in English.
}

can be as high as $20 \%$, in contrast to the observed AM1.5G efficiency of $10 \%$ [5]. In organic dye cells, the iodine in the electrolyte absorbs a part of the blue incident light, resulting in a decreased blue response [6].

Conversion of the incident solar spectrum to monochromatic light would greatly increase the observed efficiency. To this end, one needs to modify the energy of incident photons such that $E_{\mathrm{ph}}$ equals $E_{g}$ or is slightly larger. To distinguish any modification of photon energy from the distinct terms down and up conversion, we will use the term spectral down conversion (SDC) or spectral up conversion (SUC) throughout this paper. Down conversion strictly is used for the conversion of exactly one high-energy photon to exactly two lowerenergy photons, whereas up conversion is the conversion of exactly two low-energy photons to exactly one higher-energy photon.

Spectral down conversion was suggested in the 1970 s to be used in so-called luminescent concentrators that were attached onto a solar cell [7-10]. In these concentrators, organic dye molecules absorb incident light and reemit this at a red-shifted wavelength. Internal reflection ensures collection of all the reemitted light in the underlying solar cells. It was suggested that a number of different organic dye molecules be used of which the reemitted light was matched for optimal conversion by different solar cells. This is similar to using a stack of multiple solar cells, each sensitive to a different part of the solar spectrum. The expected high efficiency in practice was not reached as a result of not being able to 
meet the stringent requirements for the organic dye molecules, such as high quantum efficiency and stability, and the transparency of collector materials in which the dye molecules were dispersed [7-10].

Recently, quantum dots (QDs) were proposed for use in luminescent concentrators instead of organic dye molecules [11-13]. Quantum dots are nanometer-sized semiconductor crystals of which the emission wavelength can be tuned by their size as a result of quantum confinement $[14,15]$. The advantages of QDs with respect to organic dye molecules are their high brightness, stability, and quantum efficiency [16]. In addition, QDs absorb all the light of a wavelength smaller than the absorption maximum, in contrast to the small-band absorption of dye molecules. As an example, CdSe/ZnS core-shell QDs of $4 \mathrm{~nm}$ diameter have an emission maximum around $550 \mathrm{~nm}$ [17-19], which would be ideally suited for amorphous silicon solar cells.

A simple and potentially cheap way of employing the principle of SDC is to coat a solar cell with a transparent layer that contains a spectrum-shifting moiety. Such a planar spectral down converter can be applied to existing solar cells without modifications to the solar cell design. Hence, optimization of the converter can be done independently of the solar cell. Optimization of the converter should lead to an increase in the conversion efficiency of the solar cell. An $8 \%$ relative increase in conversion efficiency was reported in the case of a $\mathrm{CdS} / \mathrm{CdTe}$ solar cell, where the coating in which a fluorescent coloring agent was introduced increased the sensitivity in the blue [20]. Recent results on coating a multicrystalline silicon solar cell indicate a $6 \%$ relative increase in conversion efficiency [21]. This species has an absorption band around $400 \mathrm{~nm}$ and a broad emission between 450 and $550 \mathrm{~nm}$. As QDs have a much broader absorption, it is expected that in potential the deployment of QDs in planar converters could lead to relative efficiency increases of 20-30\%. Besides QDs, other materials have been suggested such as rare-earth ions [22] and dendrimers [23]. A maximum increase of $22.8 \%$ was calculated for a thin film coating of $\mathrm{KMgF}_{3}$ doped with $\mathrm{Sm}$ on top of a CdS/CdTe solar cell, while experimental results show an increase of 5\% [24]. Spectral down conversion employing QDs in a polymer composite has been demonstrated in a light-emitting diode (LED) where a GaN LED was used as an excitation source $\left(\lambda_{\mathrm{em}}=425 \mathrm{~nm}\right)$ for QDs emitting at $590 \mathrm{~nm}$ [25].

In this paper, we will explore the feasibility of QD use in planar converters on top of solar cells. First, a quick method is used to assess the effects of varying emission wavelength on solar cell performance using small-band QD emission spectra. Second, a more detailed method is used, where the effect of the incorporation of QDs in a plastic layer on the incident solar spectrum is determined. This includes different QD sizes (i.e., absorption/emission maxima) and concentrations. The modified spectrum is then used as input in solar cell simulation programs suited for either crystal-

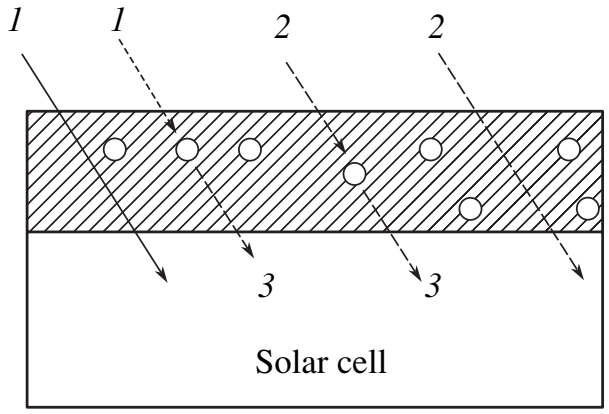

Fig. 1. Schematic drawing of the studied configuration. A plastic layer containing quantum dots is applied on top of a solar cell. Both blue (1) and green (2) light are absorbed by the quantum dot and reemitted in the red (3), which is subsequently absorbed in the solar cell. Also, unabsorbed blue and green light enters the solar cell as well.

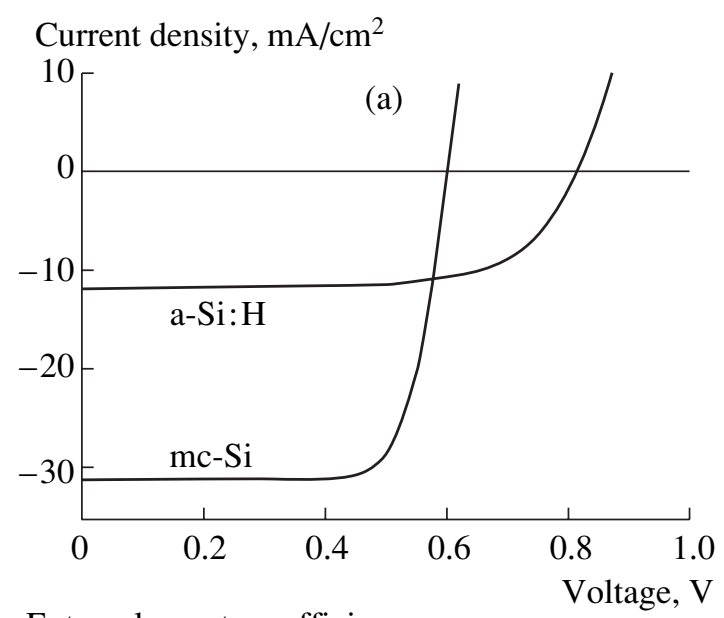

External quantum efficiency

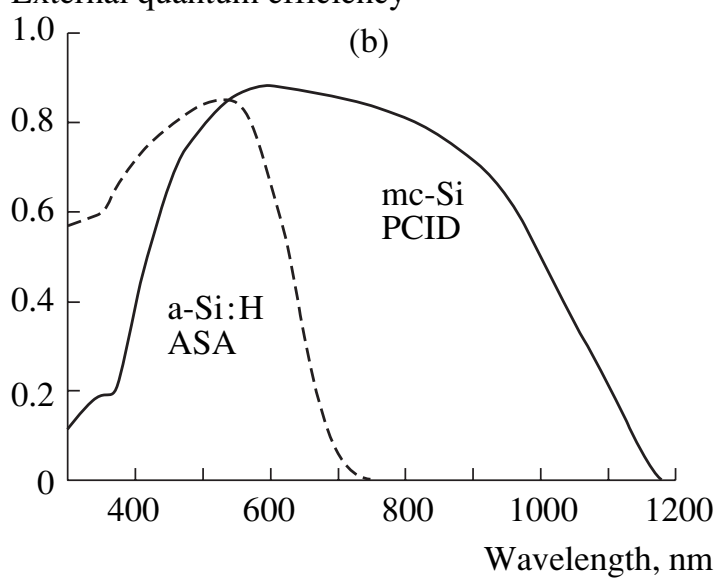

Fig. 2. Performance of the two solar cells, mc-Si and a-Si:H: (a) current-voltage characteristics, (b) spectral response.

line or amorphous silicon. We will study the effects of QD size (spectral properties) and concentration of the conversion efficiency and will determine the optimum for both the mc-Si and a-Si:H solar cell. As the spectral response of these types of cells differs, we expect that 


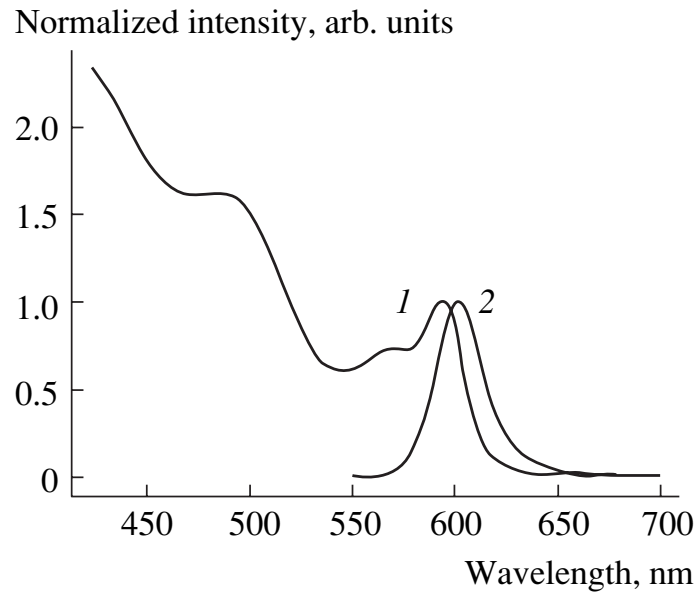

Fig. 3. Normalized absorption (1) and emission (2) spectrum of CdSe nanocrystals $4.3 \mathrm{~nm}$ in diameter, capped with TOPO/TOP/HDA (data from S.F. Wuister (2003); see also [30]).

the optimum combination of QD size and concentration will also differ.

\section{METHODOLOGY}

The configuration that is studied is depicted in Fig. 1. A plastic layer containing quantum dots is applied on top of a solar cell. The size of the quantum dots is chosen such that their emission maximum is in the red part of the spectrum; thus, they will absorb both blue and green incident light. We implicitly assume that the solar cell has an optimum spectral response in the red. Depending on the concentration of QDs, unabsorbed blue and green light also enters the solar cell. Of course, highly transparent plastics are to be used.

The effects of QDs in planar converters will be assessed on standard baseline solar cells that are reproducibly manufactured at ECN and Utrecht University. We will first describe the two types of solar cells under investigation, i.e., multicrystalline silicon and hydrogenated amorphous silicon. Their performance will be simulated under standard AM1.5G spectral conditions using software specifically designed for either material.

Inclusion of QDs in a planar converter on top of a solar cell leads to spectral changes. We will first study the effect of small-band emission spectra of QDs on the

Solar cell performance parameters calculated with PC1D (mc-Si) and ASA (a-Si:H)

\begin{tabular}{l|c|c}
\hline & $\mathrm{mc}-\mathrm{Si}$ & a-Si:H \\
\hline$I_{\mathrm{sc}}, \mathrm{mA} / \mathrm{cm}^{2}$ & 31.19 & 11.92 \\
$V_{\mathrm{oc}}, \mathrm{V}$ & 0.6028 & 0.8135 \\
$F F$ & 0.7707 & 0.6753 \\
$\eta, \%$ & 14.49 & 6.548 \\
\hline
\end{tabular}

solar cell performance parameters. This will quickly show the potential benefits of QD use. Finally, a more thorough analysis will be carried out that includes the modifications of the AM1.5G spectrum due to QD absorption and emission.

\subsection{Solar Cell Configurations}

The standard baseline $n-p-p^{+}$mc-Si cell has parameters that are typical of low-cost commercial products, including series resistance, shunt conductance, and a second diode [26]. It measures $10 \times 10 \mathrm{~cm}^{2}$ in area and has a shallow diffused emitter of $50 \Omega /$ sq. The thickness of the cell is $300 \mu \mathrm{m}$. The front broadband reflectance is $9 \%$ across the solar spectrum. The front surface is coated with a $71 \mathrm{~nm}$ thick silicon nitride antireflection coating with a refractive index $n=2.1$. The thickness of the back-surface field (BSF) is $9 \mu \mathrm{m}$ and has a $p^{+}$doping level of $4 \times 10^{18} \mathrm{~cm}^{-3}$. The performance of the solar cell is simulated with the simulation program PC1D (version 5.8) [27, 28]. The calculated performance parameters (short-circuit current $I_{\mathrm{sc}}$, open-circuit voltage $V_{\text {oc }}$, fill factor $F F$, efficiency $\eta$ ) are given in the table; the current-voltage characteristics and spectral response are shown in Fig. 2.

The standard baseline a-Si:H cell has the usual layer configuration glass/TCO/p-a-SiC:H/i-a-Si:H/n-a-Si:H/Ag, with layer thicknesses of $1 \mathrm{~mm}, 1 \mu \mathrm{m}$, and 8, 500, 20, and $200 \mathrm{~nm}$, respectively [3]. TCO is a transparent conductive coating, such as $\mathrm{SnO}_{2}$. Activation energies for the $n$ and $p$ layers are 0.24 and $0.46 \mathrm{eV}$, respectively. Solar cell performance is simulated with the program ASA (version 3.3), which includes specific features of amorphous semiconductors, such as sloped band edges and midgap dangling bond density models $[3,29]$. The calculated performance is compared to the performance of the mc-Si cell in the table and Fig. 2.

\subsection{Small-Band Spectrum}

A simple approach that allows the selection of the most appropriate QD size entails simulation of solar cell performance employing small-band QD emission spectra alone. To this end, we used normalized emission spectra and scaled them such that the integrated spectral density was $500 \mathrm{~W} / \mathrm{m}^{2}$. A typical normalized emission spectrum is shown in Fig. 3 [30]. These scaled spectra were then used as input for the simulation programs PC1D and ASA. We varied the center emission wavelengths in $50 \mathrm{~nm}$ steps in the range $400-1000 \mathrm{~nm}$ and simulated solar cell performance.

\subsection{Modified AM1.5G Spectrum}

In the configuration shown in Fig. 1, the incident AM1.5G spectrum converted to an amount of photons per wavelength $\Phi_{s}(\lambda)$ will be modified by absorption of photons. First, the amount of absorbed photons $\Phi_{a}(\lambda)$ is determined from the QD absorption spectrum, which 
depends on the QD size, their concentration in the converter layer, and the thickness of this layer. This absorbed amount is subtracted from the AM1.5G spectrum:

$$
\Phi_{s a}(\lambda)=\Phi_{s}(\lambda)-\Phi_{a}(\lambda)
$$

As the QDs reemit light at a red-shifted wavelength, the amount of emitted photons $\Phi_{e}(\lambda)$ is calculated from the QD emission spectrum. To this end, data for quantum efficiency is assumed, as well as the assumption that $3 / 4$ of the emitted photons is directed towards the underlying solar cell due to internal reflection in the converter layer [13].

The amount of emitted photons is then added to the already modified AM1.5G spectrum:

$$
\Phi_{s a e}(\lambda)=\Phi_{s a}(\lambda)+\Phi_{e}(\lambda) .
$$

Finally, the resulting spectrum serves as input for the solar cell simulation models.

The most common approach to calculate absorption of photons is by using the Lambert-Beer equation: the photon flux density $\Phi(x, \lambda)$ after passing a distance $x$ in a film with absorption coefficient $\alpha(\lambda)$ is reduced with a factor $\exp [-\alpha(\lambda) x]$, which can be written as

$$
\Phi(x, \lambda)=\Phi^{0}(\lambda) \exp [-\alpha(\lambda) x],
$$

where $\Phi^{0}(\lambda)$ is the incident photon flux density. The exponential term equals $\alpha(\lambda) x=\varepsilon_{\lambda} C D$, where $\varepsilon_{\lambda}$ is the molar extinction coefficient $\left(\mathrm{M}^{-1} \mathrm{~cm}^{-1}\right), C$ is the chromophore concentration (M), and $D$ is the thickness of the film $(\mathrm{cm})$. The molar extinction coefficient can be measured directly or determined from measurement of the absorption spectrum (see below). The chromophore or QD concentration can be varied at will, from the nanomolar to the millimolar range. The thickness of the film (converter) will typically vary between about one micrometer and a few millimeters. In the following, we will describe in detail the followed procedure for QDs emitting at $603 \mathrm{~nm}$.

Quantum dots of high quantum yield $\left(\eta_{\mathrm{em}}=0.8\right)$ are routinely synthesized in our laboratory following a single-step route using trioctylphosphine oxide (TOPO) and hexadecylamine (HDA) [30]. The resulting typical (normalized) absorption $A_{n}(\lambda)$ and emission $E_{n}(\lambda)$ spectra are shown in Fig. 3. These spectra have been normalized with respect to the absorption and emission maximum occurring at 594 and $603 \mathrm{~nm}$, respectively. The normalized absorption spectrum can be converted to a wavelength-dependent molar extinction coefficient but requires the determination of the QD concentration, which is cumbersome and time-consuming. Instead, we used the reported cubic relationship between the molar extinction coefficient and particle size as reported by Leatherdale et al. [31] (radius) and Schmelz et al. [32] (diameter). The particle diameter is determined from the absorption maximum at $594 \mathrm{~nm}$ using the relation between the absorption maximum and particle diameter reported in the literature [33-35], i.e., $4.24 \mathrm{~nm}$ in diameter. Thus, the QD radius $a$ determined from experimental data is $2.12 \mathrm{~nm}$. The absorption spectrum $A(\lambda)$ is scaled such that the molar extinction coefficient $\varepsilon_{\lambda}$ at $350 \mathrm{~nm}$ equals $\varepsilon_{\lambda}\left(\mathrm{M}^{-1} \mathrm{~cm}^{-1}\right)=\left(1.438 \times 10^{26}\right) a^{3}$, as reported by Leatherdale et al. [31]. The calculated $\varepsilon_{\lambda}$ at $350 \mathrm{~nm}$ is $\varepsilon_{350}=1.37 \times 10^{6} \mathrm{M}^{-1} \mathrm{~cm}^{-1}$. The data reported for the molar extinction coefficient by Schmelz et al. [32] give $\varepsilon_{602}=2.65 \times 10^{5} \mathrm{M}^{-1} \mathrm{~cm}^{-1}$ for their $4.5 \mathrm{~nm}$ diameter CdSe particle. From their data, one can infer that $\varepsilon_{602} / \varepsilon_{350} \approx 4.3$, so there is reasonable agreement with the data from Leatherdale et al. with only a difference of about $15 \%$ in $\varepsilon_{350}$.

The amount of absorbed photons $\Phi_{a, 603}(D, \lambda)$ in the converter of thickness $D$ and containing QDs of emission wavelength $603 \mathrm{~nm}$ is now

$$
\Phi_{a, 603}(D, \lambda)=\Phi_{s}(\lambda) \exp \left(-\varepsilon_{\lambda} C D\right),
$$

and the modified amount $\Phi_{s a, 603}(D, \lambda)$ is calculated with Eq. (1):

$$
\begin{gathered}
\Phi_{s a, 603}(D, \lambda)=\Phi_{s}(\lambda)-\Phi_{a, 603}(D, \lambda) \\
=\Phi_{s}(\lambda)\left[1-\exp \left(-\varepsilon_{\lambda} C D\right)\right] .
\end{gathered}
$$

Now, photons will be emitted at quantum efficiency $\eta_{\mathrm{em}}=0.8$. Further assuming isotropic emission and internal reflection, $75 \%$ of the emitted photons will reach the solar cell: $\eta_{t}=0.75$. Therefore, the integrated amount of emitted photons equals $\eta_{t} \eta_{\mathrm{em}}$ times the integrated amount of absorbed photons,

$$
\eta_{t} \eta_{\mathrm{em}} \int \Phi_{a, 603}(D, \lambda) d \lambda=\int \Phi_{e, 603}(D, \lambda) d \lambda=k,
$$

where $\Phi_{e, 603}(D, \lambda)$ is scaled to $\Phi_{e, 603}(\lambda)$ such that

$$
k=\frac{\int \Phi_{e, 603}(D, \lambda) d \lambda}{\int \Phi_{e, 603}(\lambda) d \lambda} .
$$

The normalized amount of emitted photons as a function of wavelength $\Phi_{e, 603}(\lambda)$ is calculated from the normalized emission spectrum $E_{n}(\lambda)$.

The amount of emitted photons $\Phi_{e, 603}(D, \lambda)$ is then added to the already modified AM1.5G spectrum $\Phi_{s a, 603}(D, \lambda)$ with Eq. (2) to yield

$$
\Phi_{s a e, 603}(D, \lambda)=\Phi_{s a, 603}(D, \lambda)+\Phi_{e, 603}(D, \lambda) .
$$

The modified spectrum $\Phi_{s a e, 603}(D, \lambda)$ serves as input for the solar cell simulation models.

As an example, Fig. 4 shows the result of this procedure for a QD with $\lambda_{\mathrm{em}}=603 \mathrm{~nm}$, which also illustrates the effect of QD concentration. For a converter thickness $D=1 \mathrm{~mm}$, we have varied the QD concentrations from $1 \mu \mathrm{M}$ to $1 \mathrm{mM}$. At a concentration of $1 \mu \mathrm{M}$, an 
Photon flux density, $10^{19} \mathrm{~m}^{-2} \mathrm{~s}^{-1}$

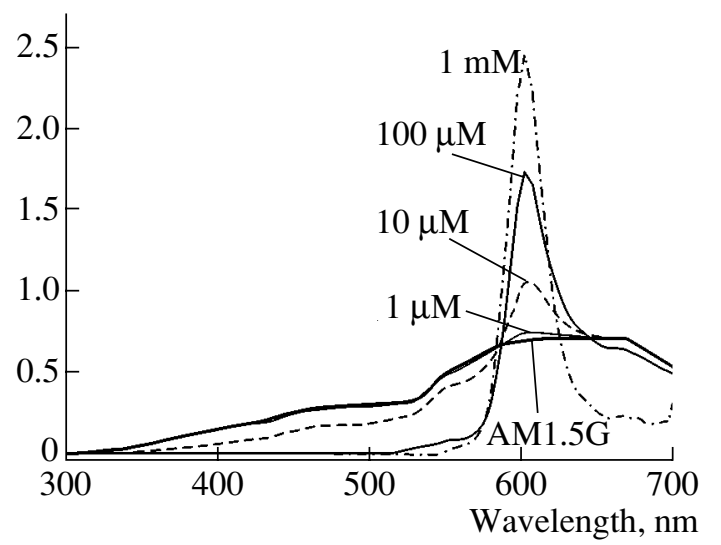

Fig. 4. Calculated modified spectra for various molar QD concentrations that notably influence the AM1.5G spectrum, i.e., 1,10 , and $100 \mu \mathrm{M}$ and $1 \mathrm{mM}$.

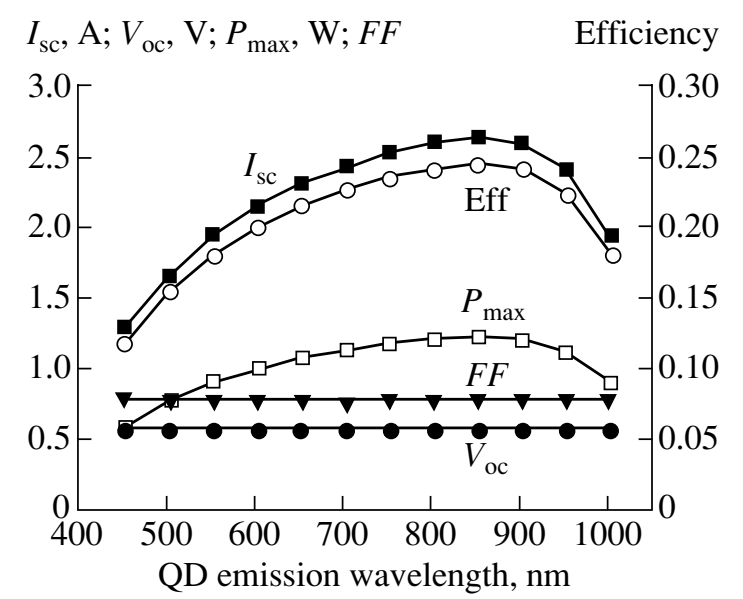

Fig. 5. Effect of small-band QD emission $\left(500 \mathrm{~W} / \mathrm{m}^{2}\right)$ on the parameters $I_{\mathrm{sc}}, V_{\mathrm{oc}}, F F, P_{\max }$, and efficiency (Eff) of the mc-Si solar cell as a function of center emission wavelength. Left-hand scale: $I_{\mathrm{sc}}, V_{\mathrm{oc}}, P_{\mathrm{max}}$, and $F F$; right-hand scale: efficiency.

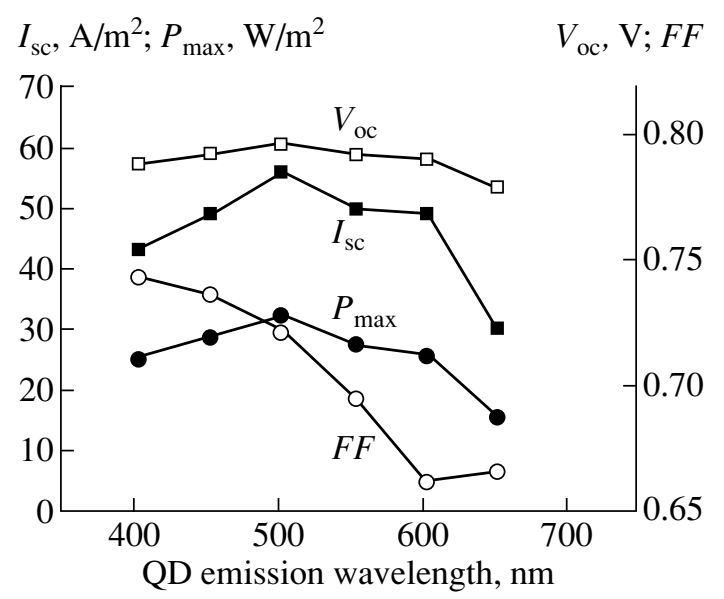

Fig. 6. Effect of small-band QD emission $\left(500 \mathrm{~W} / \mathrm{m}^{2}\right)$ on the parameters $I_{\mathrm{sc}}, V_{\mathrm{oc}}, F F$, and $P_{\mathrm{max}}$ of the a-Si:H solar cell as a function of center emission wavelength. Left-hand scale: $I_{\mathrm{sc}}$ and $P_{\max }$, right-hand scale: $V_{\mathrm{oc}}$ and $F F$. appreciable amount of photons is absorbed in the blue part of the AM1.5G spectrum, while the modified spectrum is increased at the QD emission wavelength. For higher concentrations, this effect is clearly much stronger. Note that the product $C D$ determines the amount of spectral change. Optimum values for QD concentration are related to the thickness of the converter.

In order to study the effect of different QD size, we shifted the emission spectra in the emission wavelength range $300-700 \mathrm{~nm}$ with $50 \mathrm{~nm}$ steps. We assumed that the form of spectra remains identical, which is reasonable, as seen in reported absorption/emission spectra as a function of QD size [30-35]. The particle diameters are again determined from the absorption maxima using the relation between the absorption maximum and particle diameter reported in the literature [33-35]. The extinction coefficients are then calculated with the equation from Leatherdale et al. [31]. The modified spectra $\Phi_{s a, \lambda_{\mathrm{em}}}(D, \lambda)$ are calculated following the procedure described above.

\section{RESULTS AND DISCUSSION 3.1. Small-Band Spectrum}

The effect of incident small-band spectra on solar cell performance can be easily simulated. We varied the center emission wavelengths of the QDs in 50-nm steps in the range $400-1000 \mathrm{~nm}$, scaled to $500 \mathrm{~W} / \mathrm{m}^{2}$. The results obtained with $\mathrm{PC1D}$ for the $\mathrm{mc}-\mathrm{Si}$ cell are shown in Fig. 5. A clear increase in short-circuit current from 1.3 A at a QD emission wavelength of $453 \mathrm{~nm}$ to an optimum of $2.6 \mathrm{~A}$ at $853 \mathrm{~nm}$ is observed, with a concomitant increase in conversion efficiency from 12 to $24 \%$. Both the fill factor and the open-circuit voltage hardly change. The optimum wavelength of $853 \mathrm{~nm}$ does not coincide with the wavelength where the spectral response is at its maximum (see Fig. 2b). At this optimum of about $600 \mathrm{~nm}$, the spectral response is $11 \%$ larger than the one at $850 \mathrm{~nm}$. At present, we cannot explain this. The performance parameters compare most favorably to the ones obtained from simulation with an AM1.5G spectrum at $500 \mathrm{~W} / \mathrm{m}^{2}$ spectral density, i.e., short-circuit current $I_{\mathrm{sc}}=1.559 \mathrm{~A}$, open-circuit voltage $V_{\mathrm{oc}}=0.5851 \mathrm{~V}$, fill factor $F F=0.7937$, and efficiency $\eta=14.48 \%$. Clearly, if the complete AM1.5G spectrum could be converted to only one small-banded wavelength region, the optimum center wavelength should be around $850 \mathrm{~nm}$, which leads to a near doubling of conversion efficiency.

The effects on hydrogenated amorphous silicon solar cells are much less spectacular. The simulation results with ASA are shown in Fig. 6. Clearly, an optimum in short-circuit current exists at a QD emission wavelength of $500 \mathrm{~nm}$, i.e., $I_{\mathrm{sc}}=55.63 \mathrm{~A} / \mathrm{m}^{2}$. This optimum coincides with the optimum in the spectral response curve (Fig. 2b). However, the optimum is lower than the short-circuit current calculated using the AM1.5G spectrum at $500 \mathrm{~W} / \mathrm{m}^{2}$ spectral density: $I_{\mathrm{sc}}=$ 


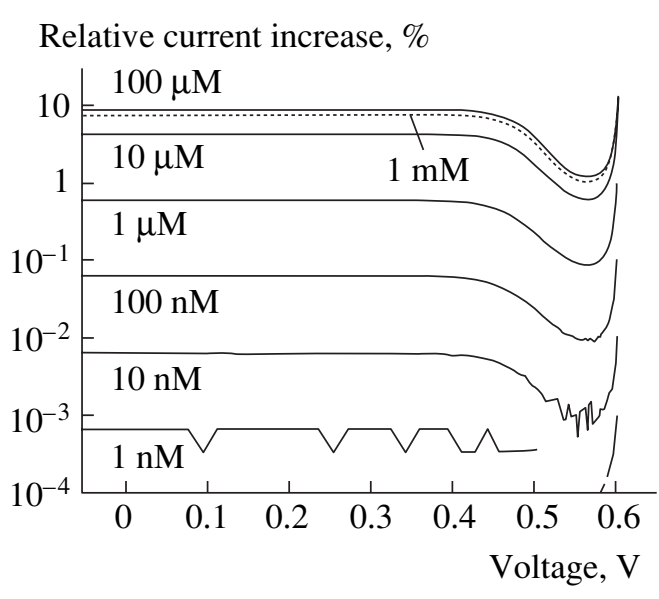

Fig. 7. The effect of QD concentration on the current of the mc-Si solar cell as a function of cell voltage, shown as the current increase relative to the base case (AM1.5G).

$59.53 \mathrm{~A} / \mathrm{m}^{2}$. This is most probably caused by the smallbanded spectral response of the a-Si:H cell.

\subsection{Modified AM1.5G Spectrum}

As the optimum center emission wavelength of QDs in the planar converter on top of an mc-Si solar cell appears to be around $600 \mathrm{~nm}$, we simulated the solar cell performance changes for the QDs with $\lambda_{\mathrm{em}}=$ $603 \mathrm{~nm}$ for a concentration range from $1 \mathrm{nM}$ to $1 \mathrm{mM}$. The effects on the AM1.5G spectrum were already shown in Fig. 4 for a concentration range from $1 \mu \mathrm{M}$ to $1 \mathrm{mM}$.

Figure 7 shows the relative current increase of the mc-Si solar cell as a function of cell voltage for the concentration range from $1 \mathrm{nM}$ to $1 \mathrm{mM}$. A clear constant increase in short-circuit current of about $6 \times 10^{5 \% / \mathrm{M} \text { is }}$ observed up to a concentration of $1 \mu \mathrm{M}$. For higher concentrations, the effect levels off and even decreases at a concentration of $1 \mathrm{mM}$. Here, the beneficial effect is counteracted by the increased absorption due to this high concentration. The effect on all solar cell performance parameters is shown in Fig. 8. Clearly, the effects start to occur at $1 \mu \mathrm{M}$. While both short-circuit current and maximum generated power $P_{\max }$ follow similar behavior, the open-circuit voltage and fill factor only slightly decrease. The efficiency depicted in this figure does not equal $F F I_{\mathrm{sc}} V_{\mathrm{oc}}$. As the QD concentration increases, the spectral density incident on the solar cell decreases. We calculated the efficiency based on this decreasing intensity and not based on $1000 \mathrm{~W} / \mathrm{m}^{2}$. Therefore, the effect on efficiency is most spectacular: an increase of $30-40 \%$ is calculated.

It should be noted that, in practice, the results for the highest concentrations $(0.1-1 \mathrm{mM})$ will not be as high as those presented here, because reabsorption is not taken into account in our simulations. This will lower the amount of emitted photons that enter the solar cell, which will be apparent in a lower peak in the modified
Relative change in variable, $\%$

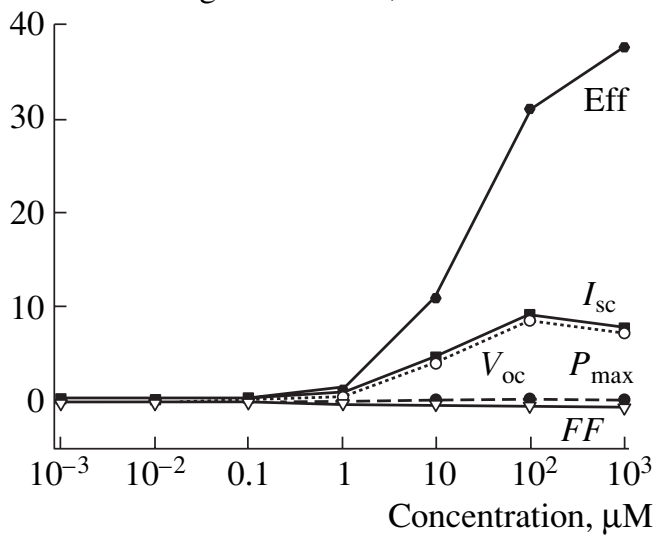

Fig. 8. The absolute change of the variables $I_{\mathrm{sc}}, V_{\mathrm{oc}}, F F$, $P_{\text {max }}$, and efficiency (Eff) of the mc-Si solar cell as a function of QD concentration.

spectrum at the QD emission center wavelength. Nevertheless, a relative increase of nearly $10 \%$ is in our opinion realizable. In addition, as the product of QD concentration and converter thickness $C D$ determines the amount of spectral change, high concentrations can be avoided in converters of larger thickness, as long as $C D$ remains constant.

For the simulation of QDs in the planar converter on top of $a$-Si:H cells, we used QDs of center emission wavelength of $503 \mathrm{~nm}$, as at this wavelength the strongest effects are expected (Fig. 6). The results for the short-circuit current are shown in Fig. 9 for a concentration range from $0.1 \mu \mathrm{M}$ to $10 \mathrm{mM}$. At about a concentration of $10 \mu \mathrm{M}$, the effects on short-circuit current start to be noticeable. This concentration is one order of magnitude higher than in the case of $\mathrm{mc}-\mathrm{Si}$. Also, in

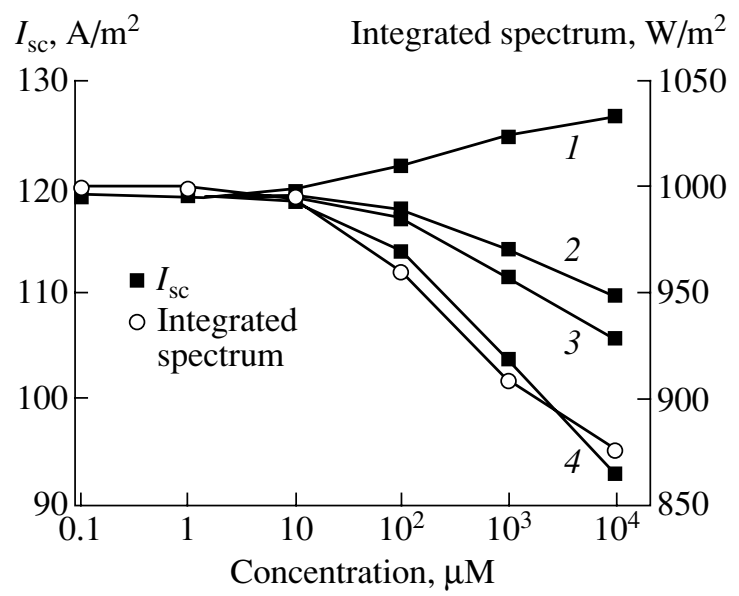

Fig. 9. The relative change of the short-circuit current $I_{\mathrm{sc}}$ of the a-Si:H solar cell as a function of QD concentration for combinations of the quantum efficiency $\eta_{e}$ and capture efficiency $\eta_{t}:(1) \eta_{e}=1, \eta_{t}=1$; (2) $\eta_{e}=0.8, \eta_{t}=1 ;$; (3) $\eta_{e}=1$, $\eta_{t}=0.75$; and (4) $\eta_{e}=0.8, \eta_{t}=0.75$. The integrated spectrum is shown on the right-hand scale for $\eta_{e}=0.8, \eta_{t}=0.75$. 
contrast to $\mathrm{mc}-\mathrm{Si}$, here, the short-circuit current decreases by about $10 \%$ for a concentration of $1 \mathrm{mM}$, in close correspondence to the decrease in spectral intensity (Fig. 9). This has clearly to do with the amount of absorbed photons balanced with the emitted photons in relation to the spectral response. The aim of applying QDs as wavelength shifters is only sensible when an appreciable difference exists in spectral response between the QD center emission wavelength and the lower wavelengths. As the spectral response of the a-Si:H solar cell is already high at low wavelengths, the beneficial effects, if any, will be small. As a demonstration, when the QD quantum efficiency equals unity, and when in addition all the emitted photons enter the solar cell, an increase in short-circuit current is observed of about $4 \%$ for a concentration of $1 \mathrm{mM}$, as shown in Fig. 9. Increasing either $\eta_{\mathrm{em}}$ or $\eta_{t}$ to unity still leads to a decreasing short-circuit current.

\section{CONCLUSION}

The inclusion of a planar converter that contains wavelength-shifting moieties such as quantum dots allows for a better use of the solar spectrum. However, the most beneficial effects will be accomplished if the spectral response of solar cells has a specific form such that the spectral response is low at low wavelengths and high at high wavelengths. The wavelength-shifting moieties should shift the wavelengths where the spectral response is low to wavelengths where the spectral response is high. Further, losses associated with low quantum efficiency and isotropic emission should be avoided, i.e., the quantum efficiency should be as high as possible (unity preferred) and internal reflection conditions should be optimized.

Here, we demonstrated that QDs with a center emission wavelength of $603 \mathrm{~nm}$ included in a planar converter on top of a multicrystalline solar cell are capable of increasing the short-circuit current by nearly $10 \%$. The concomitant increase in efficiency, calculated with the amount of photons incident on the solar cell, can be as high as $30-40 \%$. Simulation results for planar converters on hydrogenated amorphous silicon solar cells show no beneficial effects due to the high spectral response at low wavelength.

Experimental verification of the above results is in progress. To this end, CdSe/ZnS core/shell QDs will be dispersed in a polymer at varying concentrations. The QD/polymer solution will be subsequently spin coated on solar cells. The best polymer candidate is a polylaurylmethacrylate (PLMA) matrix, of which it is reported that the quantum efficiency of QDs is retained after dispersion in PLMA [25].

\section{ACKNOWLEDGMENTS}

We gratefully acknowledge the fruitful discussions on QDs with S. Wuister and C. de Mello Donegá (Utrecht University). Furthermore, we would like to thank the Netherlands Organization for Energy and the Environment (NOVEM) for financial support through their NEO program (contract no. 0268-02-03-04-002) and the European Commission for financial support as part of the Framework 6 integrated project FULLSPECTRUM (contract no. SES6-CT-2003-502620). Finally, we would like to thank Zh.I. Alferov, T. d'Estaintot, and A. Luque for organizing the EU-Russian Workshop "Efficient Use of Solar Spectrum in Photovoltaics," November 2-5, 2003, in St. Petersburg, Russia, where this work was discussed, and V.M. Andreev for kindly hosting this conference at the Ioffe Physicotechnical Institute, St. Petersburg (Russia).

\section{REFERENCES}

1. M. A. Green, Solar Cells: Operating Principles, Technology and Systems Application (Prentice Hall, Englewood Cliffs, N.J., 1982).

2. M. A. Green, Third Generation Photovoltaics. Advanced Solar Energy Conversion (Springer, Berlin, 2003).

3. R. E. I. Schropp and M. Zeman, Amorphous and Microcrystalline Silicon Solar Cells: Modeling, Materials, and Device Technology (Kluwer Academic, Boston, 1998).

4. W. G. J. H. M. Van Sark, in Thin Films and Nanostructures, Ed. by M. H. Francombe (Academic, San Diego, 2002), Vol. 30, p. 1.

5. R. E. I. Schropp, unpublished results.

6. P. M. Sommeling, H. C. Rieffe, J. A. M. van Roosmalen, et al., Sol. Energy Mater. Sol. Cells 62, 399 (2000).

7. R. L. Garwin, Rev. Sci. Instrum. 31, 1010 (1960).

8. W. H. Weber and J. Lambe, Appl. Opt. 15, 2299 (1976).

9. A. Goetzberger and W. Greubel, Appl. Phys. 14, 123 (1977).

10. C. F. Rapp and N. L. Boling, in Proceedings of 13th Photovoltaic Specialists Conference (Washington, DC, 1978), p. 690.

11. K. Barnham, J. L. Marques, J. Hassard, and P. O’Brien, Appl. Phys. Lett. 76, 1197 (2000).

12. A. J. Chatten, K. W. J. Barnham, B. F. Buxton, et al., Sol. Energy Mater. Sol. Cells 75, 363 (2003).

13. A. J. Chatten, K. W. J. Barnham, B. F. Buxton, et al., in Proceedings of 3rd World Congress on Photovoltaic Energy Conversion (WPEC-3), Osaka, Japan, 2003 (in press).

14. A. P. Alivisatos, J. Phys. Chem. 100, 13226 (1996).

15. S. V. Gaponenko, Optical Properties of Semiconductor Nanocrystals (Cambridge Univ. Press, Cambridge, 1998).

16. M. Bruchez, Jr., M. Moronne, P. Gin, et al., Science 281, 2013 (1998).

17. B. O. Dabbousi, J. Rodriguez-Viejo, F. V. Mikulec, et al., J. Phys. Chem. B 101, 9463 (1997).

18. F. V. Mikulec, M. Kuno, M. Bennati, et al., J. Am. Chem. Soc. 122, 2532 (2000).

19. W. G. J. H. M. Van Sark, P. L. T. M. Frederix, A. A. Bol, et al., Chem. Phys. Chem. 3, 871 (2002).

20. T. Maruyama and R. Kitamura, Sol. Energy Mater. Sol. Cells 69, 61 (2000). 
21. T. Maruyama and J. Bandai, J. Electrochem. Soc. 146, 4406 (1999).

22. R. T. Wegh, H. Donker, K. D. Oskam, and A. Meijerink, Science 283, 663 (1999).

23. J. M. Serin, D. W. Brousmiche, and J. M. J. Frechet, J. Am. Chem. Soc. 124, 11848 (2002).

24. B.-C. Hong and K. Kawano, Sol. Energy Mater. Sol. Cells 80, 417 (2003).

25. J. Lee, V. C. Sundar, J. R. Heine, et al., Adv. Mater. 12, 1102 (2000).

26. A. Polman, W. G. J. H. M. Van Sark, W. C. Sinke, and F. W. Saris, Sol. Cells 17, 241 (1986).

27. P. A. Basore and D. A. Clugston, in Proceedings of 25th IEEE Photovoltaic Specialists Conference, Washington, 1996 (IEEE, New York, 1996), p. 377.

28. P. A. Basore and D. A. Clugston, PC1D, User's Manual, Version 5.8 (Univ. of New South Wales, Sydney, Australia, 2002).
29. M. Zeman, J. van den Heuvel, M. Kroon, and J. Willemen, Amorphous Semiconductor Analysis (ASA), User's Manual, Version 3.3 (Delft Univ. of Technology, Delft, the Netherlands, 2000).

30. C. De Mello Donegá, S. G. Hickey, S. F. Wuister, et al., J. Phys. Chem. B 107, 489 (2003).

31. C. A. Leatherdale, W.-K. Woo, F. V. Mikulec, and M. G. Bawendi, J. Phys. Chem. B 106, 7619 (2002).

32. O. Schmelz, A. Mews, T. Basché, et al., Langmuir 17, 2861 (2001).

33. C. B. Murray, D. J. Norris, and M. G. Bawendi, J. Am. Chem. Soc. 115, 8706 (1993).

34. J. E. Bowen Katari, V. L. Colvin, and A. P. Alivisatos, J. Phys. Chem. 98, 4109 (1994).

35. M. Jacobsohn and U. Banin, J. Phys. Chem. B 104, 1 (2000). 